\title{
THE APPLICATION OF RAPD FINGERPRINTING TO ASSESS INBREEDING LEVELS IN THE CULTURED POPULATIONS OF GIANT FRESHWATER PRAWN, Macrobrachium rosenbergii
}

\author{
Imron\#, Dadan Sunandar, Rommy Suprapto, and Nunuk Listyowati \\ Research Institute for Freshwater Fish Breeding and Aquaculture
}

(Received 15 February 2010; Accepted 27 April 2010)

\begin{abstract}
Inbreeding has been one of central issues with regard to genetic quality of aquaculture species, including giant fresh water prawn (GFP). Conventional methods for the estimation of inbreeding level are available, such as pedigree analyses which requires a good pedigree record which, unfortunately, is rarely available. Likewise, microsatellite molecular markers commonly applied to obtain the coefficient inbreeding estimates are both laborious and expensive. Hence, an alternative method of inbreeding assessment which is relatively easy but reliable is in need. This study was aimed to explore the applicability of RAPD fingerprinting, which is known to be simple and affordable, to estimate inbreeding level of GFP population. Three GFP populations namely inbred, outbred, and farm populations with inbreeding level of $25 \%, 0 \%$, and unknown, respectively, were genotyped using five polymorphic RAPD primers. The inbreeding levels mentioned within the first two populations were determined using pedigree analysis. RAPD banding patterns were then used to calculate band sharing index (BSI) and inbreeding coefficient (F). Assessment of the applicability of inbreeding level estimates obtained by RAPD markers was performed by comparing them to those estimated by pedigree analysis. Results show that RAPD fingerprinting was capable of delineating populations differing in their inbreeding coefficients. The pattern resulted from molecular inbreeding coefficient within the inbred and outbred groups, was congruent with that shown by pedigree analysis, while the farm population showed closeness to the inbred group. While the accuracy of the estimate needs to be verified further, this study suggests that RAPD fingerprinting is applicable to estimate population inbreeding level, particularly due to its technical simplicity and cost affordability.
\end{abstract}

\section{KEYWORDS: inbreeding level, RAPD fingerprinting, giant freshwater prawn, Macrobrachium rosenbergii}

\section{INTRODUCTION}

Detrimental effects of inbreeding depression on economically important traits of aquaculture species, such as growth and reproductive performances, resistance to diseases, and tolerance to environmental stresses, have been widely acknowledged (Allendorf \& Luikart, 2007; Tave, 1999). Accordingly, many studies have been conducted to gain understanding on the circumstances promoting the emergence of it and on the measures toward controlling it (Sanchez et al., 2003; Shikano \& Taniguchi, 2003). Inherent to the effort of controlling inbreeding depression within a population is understanding on the population's inbreeding level. One would not be able to take necessary measures to control

\# Corresponding author. Research Institute for Freshwater Fish Breeding and Aquaculture, Jl. Raya Sukamandi No.2, Subang 41256, West Java, Indonesia. Tel.: +62 260520500

E-mail address: imronnawawi@yahoo.com 
the effect of inbreeding without having information on inbreeding level within the population of interest.

Inbreeding level or inbreeding coefficient refers to a measure of inbreeding within population that determines the probability that two alleles at a locus of an individual are identical by descent (Frankham et al., 2002). It can also be used to describe the proportion of loci in an individual that are homozygous. Several approaches are available to estimate inbreeding level of population namely pedigree analysis, the information of effective breeding number, and the use of molecular approaches (Allendorf \& Luikart, 2007). Estimation of inbreeding level using the first two approaches requires good records of either individual broodstock pedigree or actual breed contributing per generation, respectively. Unfortunately, this situation is a very rare case. Even within publicly-operated hatcheries, no pedigree information with respect to the broodstock usage is available. This situation makes the prediction of inbreeding coefficient within population is almost impossible. Hence, molecular-based estimates of inbreeding coefficient could serve as an alternative.

Most estimates of molecular inbreeding coefficient currently available have been generated using microsatellite marker (Bierne et al., 1998; Ditlecadet et al., 2006; Kang et al., 2006; Pariset et al., 2003; Romana-Eguia et al., 2005). This marker system is ideal as it is codominant, covers nuclear genome and highly polymorphic. Due to these beneficial features, it is often mentioned as molecular marker for the future (Wright \& Bentzen, 1994). However, microsatellite analysis demands more technical/laboratory skill and higher cost. For practical purposes, molecular marker system having characteristics of being cost effective and easy to implement is highly desirable. Randomly Amplified Polymorphic DNA (RAPD) is a PCR-based DNA fingerprinting technique that can meet these requirements. It is one of the simplest DNA genotyping methods and possesses several advantages over other molecular marker systems (Liu, 2007). Developed some 20 years ago (Williams et al., 1990), it gained popularity in the field of molecular characterization of fish populations, particularly in the area of population identification, genetic diversity, and population differentiation (Ali et al., 2004). Different from microsatellite marker however, this marker is dominant in nature. While molecular estimation of inbreeding level relies on the proportion homozygous and heterozygous states of the locus, DNA banding patterns resulting from RAPD analysis, due to its dominant nature, could not differentiate between homozygous and heterozygous states. For this reason apparently, RPAD marker system, albeit easy to implement, has not been widely used for the estimation of inbreeding coefficient of population. The only report, following extensive browsing of online resources on the relevant topic, came from Bhattacharya et al. (2003).

By making use information on the use of DNA fingerprinting for the estimation of relatedness and inbreeding in chicken (Kuhnlein et al., 1990) and goose (Grunder et al., 1994), Bhattacharya et al. (2003) implemented the use of RAPD system to estimate inbreeding coefficient within populations of cattle. Despite the ability of RAPD system to provide inbreeding coefficient in the population of interest, the accuracy of the estimates is unknown. This occurred due to the lack of comparative information on inbreeding coefficients provided by other methods such as those provided by pedigree record or effective breeding number within the cattle populations under study. Consequently, the estimate could be under or over the actual level. To examine the accuracy of the estimates of molecular inbreeding coefficient generated by RAPD marker, comparisons need to be made between those estimated by RAPD marker with those estimated by other methods (pedigree analysis).

Giant Freshwater prawn (GFP) is a species of aquaculture interest. Supply of seed for aquaculture relies mainly on hatcheries whose bloodstock obtained from grow-out pond, a practice that is susceptible from the occurrence of inbreeding. This study was aimed to elaborate the application of RAPD markers to estimate inbreeding level of population of GFP by comparing it to those obtained by alternative methods.

\section{MATERIALS AND METHODS}

\section{Animal Test and Their Pedigree- Based Inbreeding Levels}

Three GFP populations were used for the purpose of this study. The first two populations were those with known of their inbreeding levels, namely 25 and 0 percent, while the 
last population was those with unknown inbreeding level. The development of the first two groups was made possible due to the availability of live biological collections of different GFP germ plasm in the Research Institute for Freshwater Fish Breeding and Aquaculture (RIFFBA). The first two groups were formed through pedigreed mating, namely mating system by pairing individual broodstock with known pedigree. The first group, called inbred population, was population of progenies produced by mating of individual broodstocks derived from the same parental pair (full sib mating). Given this relationship, inbreeding level in the first group would be at least 25\% (Frankham et al., 2002; Nakadate et al., 2003).

The second group, called outbred population, was progenies produced by mating individual broodstocks derived from the same population but of different parental pair (Figure 1). Under these circumstances, the inbreeding level of the second group would be zero (Frankham et al., 2002). This population is referred to as RIFFBA normal stock. The actual inbreeding levels of the respective group however, may exceed that figures depending on the previous parental (grandparent) relatedness. However, due to the lack of that information, it was assumed that individuals within grandparent generation were not related.

The third group was a GFP population obtained from a private breeder group at Ciamis regency who applied a closed production system. For the purpose of this paper, from now onwards, the Ciamis population will be referred to as farm population. All production steps consisting of fry production, nursery, and growing-out and broodstock supply are performed by their group members. For business-oriented reasons, broodstock supply was obtained from growing out ponds without considering and applying genetic principles. Under these circumstances, the population is expected to experience some degree of inbreeding, a prediction that would be addressed through this study. The practice of closed production system took its formal form in 2006 when the group received subsidiary fund from the provincial government, although the practice itself might be started beforehand. The summary of the GFP populations used in this study, particularly with respect to genetic aspect, are summarized in Table 1.

\section{RAPD Genotyping}

\section{DNA Extraction}

GeneEluteGenomic mammalian genomic DNA miniprep kit (Sigma-Aldrich) was used to extract genomic DNA from individual samples. Briefly, it was performed by adding some 25 $\mathrm{mg}$ of GFP muscle tissue in to $1.5 \mathrm{~mL}$ tube, followed by the addition of $180 \mu \mathrm{L}$ of lysis solution and $20 \mu \mathrm{L}$ of protein $\mathrm{K}$ solution and the mixture was incubated at $55^{\circ} \mathrm{C}$ for $2-4$ hours until the tissue was completely digested. Following this step, the mixture was added with $200 \mu \mathrm{L}$ of $95 \%-100 \%$ ethanol, vortexed for

$\mathrm{G}(0)$

Fullsib family A Fullsib family B
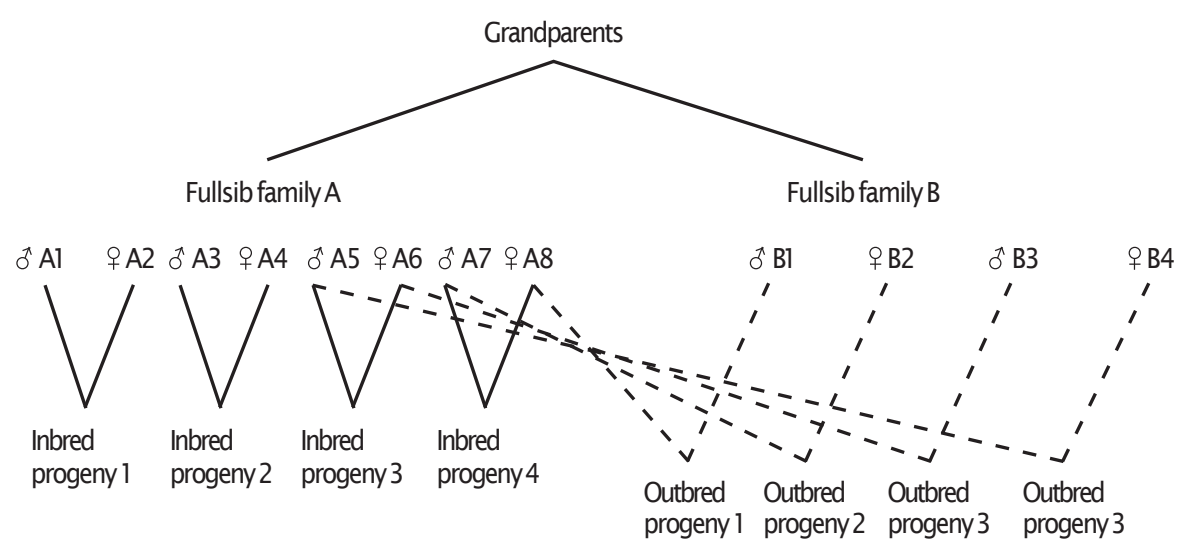

Figure1. Illustration on the mating design used to produce groups of inbred and outbred progenies. Groups of inbred progenies were produced by brother-sister mating while groups of outbred progenies were produced by mating of unrelated individual derived from different families. Population tests were those belong to $G(2)$ 
Table 1. Several main features of GFP groups used for the estimation of RAPD-based inbreeding coefficient

\begin{tabular}{lccc}
\hline \multicolumn{1}{c}{ Feat ures } & \multicolumn{3}{c}{ GFP groups } \\
\cline { 2 - 4 } & Inbreeding & Out breeding & Farm \\
\hline Origin of stock (wild/cultivated) & Cultivated & Cultivated & Cultivated \\
$\begin{array}{l}\text { Estimated time the stock under } \\
\text { domestic ation (generation)* }\end{array}$ & 13 & 13 & 5 \\
$\begin{array}{l}\text { Process of progeny (animal test) } \\
\text { establishment. }\end{array}$ & $\begin{array}{c}\text { Pedigree-based, } \\
\text { full sib mating }\end{array}$ & $\begin{array}{c}\text { Pedigree-based, } \\
\text { unrelated mating }\end{array}$ & Random mating \\
$\begin{array}{l}\text { Pedigree-based estimate of } \\
\text { inbreeding coefficient (\%) }\end{array}$ & 25 & 0 & Not available \\
Genetic management measures & n.ap & n.ap & Not applied \\
\hline
\end{tabular}

* Number of generation under domestication was determined assuming 1) interval generation of GFP is 1 year, and 2) the base year for the calculation were 1998 for inbred and outbred groups and 2006 for farm populations (see text for complete description)

** Random mating means that mating occurred in growing out pond without human intervention

5-10 sec. to make it homogenous and put in a pretreated binding column, which was prepared by adding $500 \mu \mathrm{L}$ of column preparation solution and spun at $12,000 \mathrm{~g}$ for $1 \mathrm{~min}$. Following spinning for $1 \mathrm{~min}$. at $6,500 \mathrm{~g}$, the binding column was then transferred to collection tube for twice consecutive washing, which was carried out by adding $500 \mu \mathrm{L}$ of washing solution followed by spinning at 6,500 $\mathrm{g}$ for $1 \mathrm{~min}$. The procedure was ended up with elution step which was carried by adding some $200 \mu \mathrm{L}$ of elution solution followed by $5 \mathrm{~min}$. incubation at room temperature and terminated with spinning at $6,500 \mathrm{~g}$ for $1 \mathrm{~min}$.

\section{PCR Amplification and Result Documentation}

The main disadvantage of RAPD technique for genotyping is reproducibility issue (Ali et al., 2004). Hence, optimization procedures were carried out before actual RAPD PCR was undertaken. The optimization procedures particularly were focused to obtain the best quality genomic DNA template for PCR. These included the determination of concentration, purity, and the ratio of high and low sized of genomic DNA. The best result obtained from the optimization procedures were applied to this study.

PCR reaction was conducted in $15 \mu \mathrm{L}$ volume containing $6 \mu \mathrm{L}$ of $2 \times$ mastermix microsattype it (Qiagen), $1 \mu \mathrm{L}$ of decamer primer, around 50-ng of DNA template, and $7 \mu \mathrm{L} \mathrm{H} 2 \mathrm{O}$. The primers used are listed in Table 2. Amplification of genomic DNA fragments was carried out using Mycycler thermal cycler (Biorad) for 35 cycles. The thermal profiles were $3 \mathrm{~min}$. at $94^{\circ} \mathrm{C}$ for initial denaturation, followed by 35 cycles of

Tabel 2. RAPD primer used to amplify genomic DNA fragments of three groups of GFP six Indonesian populations of Macrobrachium rosenbergii

\begin{tabular}{|c|c|c|c|}
\hline Primer & Sequence (5'-3') & Nucleotide length & $\mathrm{G}+\mathrm{C}(\%)$ \\
\hline OPZ-3 & ACA GCC TGC T & 10-mer & 60 \\
\hline OPZ-6 & AAG GCT CAC C & 10-mer & 60 \\
\hline OPZ-7 & AGA GCC GTC A & 10-mer & 60 \\
\hline OPZ-11 & AGA CGA TGG G & 10-mer & 60 \\
\hline OPZ-20 & AGC CGT GGA A & 10-mer & 60 \\
\hline
\end{tabular}


denaturation at $94^{\circ} \mathrm{C}$ for $1 \mathrm{~min}$, annealing at $37^{\circ} \mathrm{C}$ for $1 \mathrm{~min}$. and extension at $72^{\circ} \mathrm{C}$ for 2 min. The whole cycles were terminated at $72^{\circ} \mathrm{C}$ for $10 \mathrm{~min}$. The PCR product was run on horizontal agarose electrophoresis system (1.5\% agarose in $0.5 x$ Tris Boric EDTA (TBE) buffer, that was set at 10 volt and run for 6 hours. The product was then viewed using ultraviolet (UV transilluminator) following staining with ethidium bromide.

\section{Data Analyses}

RAPD fingerprinting resulting from the electrophoresis were scored as one (1) or zero (0) for the presence or absence of the bands, respectively. Size of RAPD bands was not precisely determined using individual sequences; rather they were arbitrarily determined by comparing with a known DNA size marker. Likewise, the differences in band intensity were not taken into account, namely the bands were scored the same regardless the intensity as long as they show the same size. The scores were then used to calculate two parameters, namely 1 ) band sharing index (BSI) and 2) population inbreeding coefficient (F). BSI is a system for determining diversity among members of a group (Leonard et al., 1999). It was determined following the formula of Bhattacharya et al. (2003) as follow:

$$
\mathrm{BSI}=2 \mathrm{Cab} /(\mathrm{Na}+\mathrm{Nb})
$$

where:

BSII = Band sharing index

$\mathrm{Cab}=$ Shared DNA fragments between individual $\mathrm{a}$ and $\mathrm{b}$;
$\mathrm{Na}=$ Total number of band within individual a $\mathrm{Nb}=$ Total number of band within individual $\mathrm{b}$.

Inbreeding coefficient (F) was calculated using formula of Kuhnlein et al. (1990):

$$
\mathrm{F}=(\mathrm{U}-0.416) / 0.566 ; \mathrm{U}=1 / \mathrm{N} \Sigma \mathrm{Vi}
$$

where:

$\mathrm{U}=$ Uniformity index; reflecting linier relationship between band frequency and variability,

$\mathrm{N}=$ Number of polymorphic bands scored

$\mathrm{Vi}=$ Frequency of band $-i$.

Assessment of applicability of inbreeding coefficients estimated by RAPD markers was conducted by comparing them to those predicted by pedigree analysis. Due to the lack of information on pedigree-based inbreeding level estimate within the farm population, the comparisons were restricted to the inbred and outbred populations. Two features, namely pattern and magnitude of the estimates, were used for the comparisons.

\section{Results and Discussion}

\section{General RAPD Profiles}

Results of RAPD analysis summarised in the forms of number and size of bands for each primer within the respective population is presented in Table 3. The five RAPD primers used to genotype samples within this study were found to be useful in delineating groups of GFP differing in inbreeding levels. They were all polymorphic and were able of generating polymorphic bands which are useful for the

Table 3. Summary of band number and size of each RAPD primer within the GFP populations which based on pedigree analysis, were categorized as inbred, outbred with inbreeding levels of $25 \%$ and $0 \%$, respectively, and a farm population with

\begin{tabular}{|c|c|c|c|c|c|c|}
\hline \multirow[b]{2}{*}{ Primer } & \multicolumn{2}{|c|}{ Inbreeding } & \multicolumn{2}{|c|}{ Out breeding } & \multicolumn{2}{|c|}{ Farm } \\
\hline & $\begin{array}{l}\text { Band } \\
\text { number }\end{array}$ & $\begin{array}{l}\text { Band size } \\
\text { (base pair) }\end{array}$ & $\begin{array}{c}\text { Band } \\
\text { number }\end{array}$ & $\begin{array}{l}\text { Band size } \\
\text { (base pair) }\end{array}$ & $\begin{array}{l}\text { Band } \\
\text { number }\end{array}$ & $\begin{array}{l}\text { Band size } \\
\text { (base pair) }\end{array}$ \\
\hline OPZ-3 & 11 & $750-3500$ & 13 & $400-3500$ & 7 & $800-3500$ \\
\hline OPZ-6 & 10 & $400-3000$ & 10 & $400-3000$ & 10 & $400-3000$ \\
\hline OPZ-7 & 5 & $400-1500$ & 7 & $400-1500$ & 7 & $400-1500$ \\
\hline OPZ-1 1 & 6 & $600-2570$ & 6 & $600-2570$ & 5 & $600-2570$ \\
\hline OPZ-20 & 5 & $500-1500$ & 5 & $500-1500$ & 3 & $500-1500$ \\
\hline Total & 37 & & 41 & & 32 & \\
\hline
\end{tabular}
unknown inbreeding level 
purpose of analysis (Tabel 2). Polymorphism shown by all the primers used in this study is not surprising given they were all chosen on the basis of previous preliminary experiment. Only those showing good resolution and polymorphism were used in this study.

\section{Band Sharing Index (BSI) and Inbreeding Coefficient (F)}

The band sharing index (BSI) is a measure of similarity. It is often used to make clustering of individuals based on certain marker (see e.g. Bossier et al., 2004; Dong et al., 1996; Khoo et al., 1997; Yoon \& Kim, 2001). A BSI within a group measures similarity of individuals within the group, while BSI between groups measures similarity of individuals of different groups. A group with a higher BSI value means the individuals within that group are more similar one to another relative to a group with a lower BSI value. Within this study, the highest BSI was found within the inbred group, followed by the farm and outbred groups (Table 4). These values suggest that from genetic perspective, the members of inbred population are genetically more similar one to another relative to individual member of both farm and outbred groups. This phenomenon is easily understood because individuals within the inbred group inherit alleles from the parents who shared common ancestor.

In line with the BSI, the values of RAPDbased inbreeding coefficient (F) found within the three populations show the same pattern, in which the highest $F$ value was found within the inbred, followed consecutively by the farm and the outbred groups (Table 5). Contrasting degree of inbreeding coefficient found within the inbred (the highest) and the outbred (the lowest) is exactly the same as expected. It is

Tabel 4. The values of band sharing index (BSI \pm standard deviation) within the GFP populations which based on pedigree analysis were categorized as inbred and outbred with inbreeding levels of $25 \%$ and $0 \%$, respectively, and a farm population with unknown inbreeding level

\begin{tabular}{cccc}
\hline \multirow{2}{*}{ Primer } & \multicolumn{3}{c}{ Band Sharing Index (BSI) } \\
\cline { 2 - 4 } & Inbreeding & Out breeding & Farm \\
\hline OPZ-3 & $\mathbf{0 . 8 3} \pm 0.263$ & $\mathbf{0 . 6 5} \pm 0.356$ & $\mathbf{0 . 7 6} \pm 0.213$ \\
OPZ-6 & $\mathbf{0 . 9 6} \pm 0.067$ & $\mathbf{0 . 5 7} \pm 0.193$ & $\mathbf{0 . 8 1} \pm 0.265$ \\
OPZ-7 & $\mathbf{0 . 9 5} \pm 0.136$ & $\mathbf{0 . 6 5} \pm 0.314$ & $\mathbf{0 . 7 4} \pm 0.249$ \\
OPZ-1 1 & $\mathbf{0 . 7 8} \pm 0.286$ & $\mathbf{0 . 8 2} \pm 0.044$ & $\mathbf{0 . 8 8} \pm 0.105$ \\
OPZ-20 & $\mathbf{0 . 8 5} \pm 0.133$ & $\mathbf{0 . 6 7} \pm 0.240$ & $\mathbf{0 . 9 3} \pm 0.097$ \\
\hline Average & $\mathbf{0 . 8 7} \pm 0.078$ & $\mathbf{0 . 6 7} \pm 0.091$ & $\mathbf{0 . 8 2} \pm 0.080$ \\
\hline
\end{tabular}

Tabel 5. The estimates of RAPD-based inbreeding coefficient $(F)$ within the GFP populations which based on pedigree analysis were categorized as inbred and outbred with inbreeding levels of $25 \%$ and $0 \%$, respectively, and a farm population with unknown inbreeding level

\begin{tabular}{lccc}
\hline \multirow{2}{*}{ Primer } & \multicolumn{3}{c}{ Inbreeding coefficient (F) (\%) } \\
\cline { 2 - 4 } & Inbreeding & Out breeding & Farm \\
\hline OPZ-3 & 0.82 & 0.65 & 0.70 \\
OPZ-6 & 0.71 & 0.41 & 0.50 \\
OPZ-7 & 0.75 & 0.32 & 0.68 \\
OPZ-1 1 & 0.68 & 0.29 & 0.37 \\
OPZ-20 & 0.57 & 0.15 & 0.73 \\
\hline Average & $\mathbf{0 . 7 1 \pm 0 . 0 9 3}$ & $\mathbf{0 . 3 7 \pm 0 . 1 8 6}$ & $\mathbf{0 . 5 6 \pm 0 . 1 5 7}$ \\
\hline
\end{tabular}


interesting to note that the farm population, whose information of inbreeding coefficient was not available by the time of analysis, shows a pattern close to the inbred group. Since inbreeding accumulates over time (Frankham et al., 2002), the farm population whose domestication period is shorter (Table 1), theoretically would accumulate less inbreeding coefficient. It was expected that it should have lower inbreeding coefficient than the RIFFBA normal stock since the latter has a longer domestication period (Table 1). However, this is not the case. Instead of showing the predicted pattern, the data (Table 5) shows the reverse. This suggests that from genetic point of view, the farm population has experienced a considerable level of inbreeding. This situation may occur due at least two factors, namely small population size and closed production system (Frankham et al., 2002; Tave, 1999). While the assumption of small population size per generation need to be clarified further, closed production system is really occurring and has been implemented by the farmer group for at least five generations. Overall, the resulted patterns are in line with those predicted under theoretical expectation. However, discrepancies were also observed, particularly in the magnitude of inbreeding coefficients between those predicted under pedigree and molecular analyses, as will be discussed in the next section.

\section{Comparisons of RAPD- and pedigree- based inbreeding coefficients}

Based on pedigree analysis, the populations analysed within this study have inbreeding coefficient of $25 \%$ and $0 \%$ for the inbred and outbred groups, respectively (Table 1). The RAPD-based analysis conversely, discovered figures that were much higher, more than $70 \%$ and $36 \%$ for the inbred and outbred groups, respectively (Figure 2). At a glance, both methods produce significantly different estimates and one may infer that RAPD-based estimate is unreliable. However, looking at the pattern congruency along with the history of the groups used in this study as will be discussed below, it will immediately be seen that the negative conclusion is not true.

\section{Congruency in Pattern Between RAPD - and Pedigree-Based Estimates}

Despite showing different magnitude, Figure 2 shows that inbreeding coefficient estimates generated by RAPD markers and pedigree analysis was congruent. Inbred group consistently showed higher level of inbreeding coefficient than the outbred group regardless the estimation methods used. This pattern tells us that both methods are exchangeable.

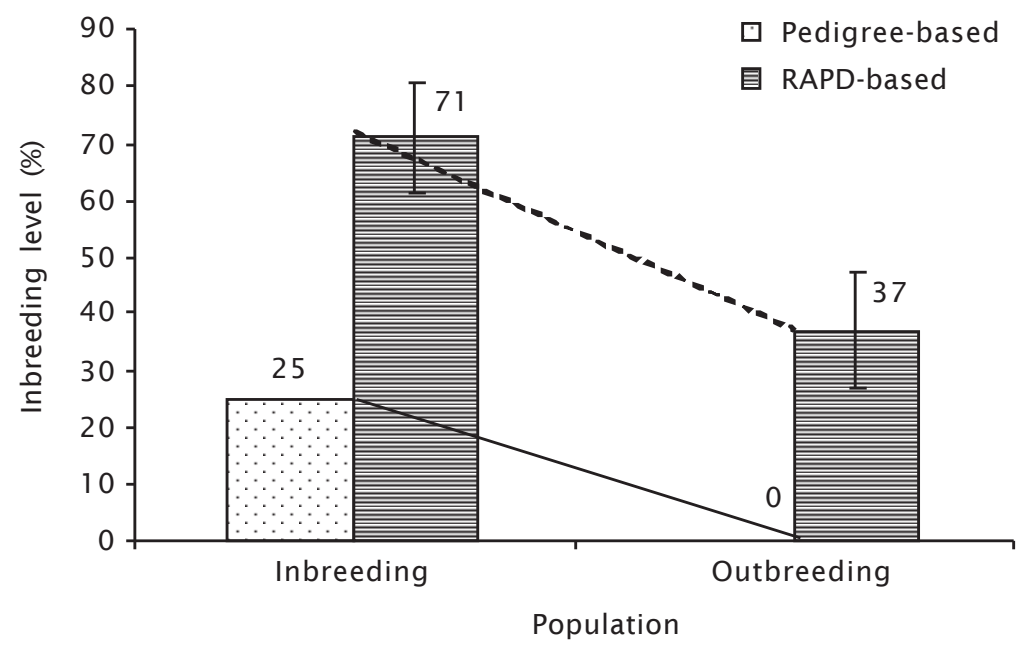

Figure 2. Comparison of inbreeding coefficients estimated by pedigree analysis and RAPD markers. Dotted and solid lines connecting both histogram series represent trendline of RAPD and pedigree-based histograms, respectively to show congruency in inbreeding estimates generated by both methods 


\section{Discrepancy in The Magnitude of RAPD- and Pedigree-Based Estimates}

Figure 2 shows that the RAPD-based estimates seem to be inflated. The coefficients were nearly three times and more than double in the inbred and outbred groups, respectively, which may cause confusion about the correct estimates. For the explanation that will be described below, author argues that within this study RAPD-based estimates of inbreeding coefficient provide more correct and reasonable than pedigree-based estimates for at least three reasons. Firstly and most importantly, it should be noted that inbreeding coefficient that was present within individual/population is accumulative over generations (Tave, 1999). Biologically, current generation accumulates inbreeding level from previous generations. While RAPD based estimates reflect the whole accumulated level of inbreeding, pedigree based estimates used in this study were determined based on the level in current generation only. They do not cover the accumulation of inbreeding that may occur in the previous generations. This assumption was made, despite illogical, due to the lack of record with regard to the effective breeding number $(\mathrm{Ne})$, number of parents effectively contribute progeny to the next generation. This information is required to determine inbreeding level.

Secondly, the GFP stocks used in this study were cultivated stocks that have been under domestication for ten generations since its launching in 2001 or some 13 generations since its establishment through breeding program in 1998. As with other farm populations in which inbreeding is something unavoidable (Allendorf \& Luikart, 2007), the RIFFBA GFP stocks must have experienced some levels of inbreeding within each generation. Compared to other aquaculture species, particularly those whose reproductive cycle can be artificially controlled, the situation has even been worse for GFP as they are asynchronous spawner and artificial induced breeding could not be applied yet. Consequently, the Ne was expected to be small and inbreeding must occur within each generation. All the abovementioned information may give support that the actual inbreeding coefficient within the RIFBA GFP stocks must be much higher than that estimated within this study.

Thirdly, the difference of inbreeding estimates between RAPD marker and pedigree analysis, ranging from $37 \%$ to $46 \%$ (Figure 2) actually may inform the inbreeding accumulation occurred within the RIFFBA GFP stocks for the last 12 generations. These figures imply that, on average, the stocks experienced the rate of inbreeding coefficient accumulation of $3 \%-4 \%$ per generation. Considering the previous illustration, this prediction is sensible. Therefore, despite quite surprising, the RAPDbased inbreeding coefficient discovered within the current study is reasonable and may reflect the true situation.

A similar explanation also holds for the farm population. A closed production system along with the absence of standard procedures ensuring the maintenance of genetic quality, have lead to the quick accumulation of inbreeding coefficient within the population. The fact that inbreeding coefficient of this population close to that of the inbred group of RIFFBA GFP stock suggested that similar genetic management may have been applied by both groups of GFP hatcheries.

The success to employ the simple molecular method such as RAPD to estimate population inbreeding level may provide quick solution for the problem arises in production process, particularly when information is required whether genetics or environmental factors are involved. It is also potential to be incorporated in genetic quality monitoring for both aquaculture and fishery management. Inbreeding estimation through the use of RAPD as described in this study for fisheries and aquaculture purposes is the first ever conducted. Earlier use of this technique had been applied to cattle (Bhattacharya et al., 2003), and poultry (Grunder et al., 1994; Kuhnlein et al., 1990). However, different from this study, those previous studies did not include prior information with regard to the inbreeding levels within these populations.

Despite the success, further refinements and verification need to be made to obtain more reliable estimate. For instance, despite congruent pattern and reasonable magnitude, the consistency of the estimate across RAPD primers was quite low. This is indicated by the relatively high value of standard deviation (Table 5). This issue could be addressed by screening more primers that more polymorphic primers with high resolution banding pattern can be discovered. Running more primers will reduce variation and improve reliability. For the 
purpose of verification, RAPD-based technique could be applied to population whose information of pedigree-based inbreeding coefficients is more accurate. Additionally, it can also be made by comparing to the results obtained from the analysis using other molecular tools such as microsatellite DNA markers.

\section{CONCLUSION}

RAPD markers have been proved to be applicable and useful in delineating GFP populations differing in inbreeding levels. Despite requirement of further calibration and verification, considering its technical simplicity and cost efficiency, it has a potential to be applied in genetic monitoring for both aquaculture and fishery management purposes.

\section{ACKNOWLEDGEMENTS}

Authors would like to thank all team members of the genetic laboratory group at the RIFFBA for sharing time, materials and knowledge during the analysis. This research was funded by research grant of the Ministry of National Education fiscal year 2009 to the Agency for Research of Marine and Fisheries.

\section{REFERENCES}

Ali, B.A., Huang, T.-H., Qin, D.-N., \& Wang, X.M. 2004. A review of random amplified polymorphic DNA (RAPD) markers in fish research, Reviews in Fish Biology and Fisheries, 14: 443-453.

Allendorf, F.W. \& Luikart, G. 2007. Conservation and the genetics of populations. Blackwell Publishing Ltd, Victoria, Australia, $642 \mathrm{pp}$.

Bhattacharya, T.K., Kumar, P., Joshi, J.D., \& Kumar, S. 2003. Estimation of inbreeding in cattle using RAPD markers. J. of Dairy Research, 70: 127-129.

Bierne, N., Launey, S., Naciri-Graven, Y., \& Bonhomme, F. 1998. Early Effect of Inbreeding as Revealed by Microsatellite Analysis on Ostrea edulis Larvae. Genetics, 148: 1893-1906.

Bossier, P., Xiaomei, W., Catania, F., Dooms, S., Van Stappen, G., Naessens, E., \& Sorgeloos, P. 2004. An RFLP database for authentication of commercial cyst samples of the brine shrimp Artemia spp. (International Study on Artemia LXX). Aquaculture, 231: 93-112.

Ditlecadet, D., Dufresne, F., Le Francois, N.R., \& Blier, P.U. 2006. Applying microsatellites in two commercial strains of Arctic charr (Salvelinus alpinus): Potential for a selective breeding program. Aquaculture, 257: 37-43.

Dong, S., Taniguchi, N., \& Tsuji, S. 1996. Identification of clones of Ginbuna, Carassius langsdorfii by DNA fingerprinting and isozyme pattern. Nippon Suisan Gakkaishi (Japanese Edition), 62: 747-753.

Frankham, R., Ballou, J.D., \& Briscoe, D.A. 2002. Introduction to conservation genetics. Cambridge University Press, Cambridge, $617 \mathrm{pp}$.

Grunder, A.A., Sabour, M.P., \& Gavora, J.S. 1994. Estimates of relatedness and inbreeding in goose strains from DNA fingerprints. Animal Genetics, 25: 135-138.

Kang, J.H., Noh, J.K., Kim, J.H., Lee, J.H., Kim, H.C., Kim, K.K., Kim, B.S., \& Lee, W.J. 2006. Genetic relationship between broodstocks of olive flounder, Paralichthys olivaceus (Temminck and Schlegel) using microsatellite markers. Aquaculture Research, 37 : 701-707.

Khoo, G., Loh, E.Y.F., Lim, T.M., \& Phang, V.P.E. 1997. Genetic variation in different varieties of Siamese fighting fish using isoelectric focusing of sarcoplasmic proteins. Aquaculture International, 5: 537-549.

Kuhnlein, U., Zadworny, D., Dawe, Y., Fairfull, R.W., \& Gavora, J.S. 1990. Assessment of inbreeding by DNA fingerprinting: Development of calibration curve using defined strains of chickens. Genetics, 125: 161-165.

Leonard, A.C., Franson, S.E., Hertzberg, V.S., Smith, M.K., \& Toth, G.P. 1999. Hypothesis testing with the similarity index. Molecular Ecology, 8: 2105-2114.

Liu, Z. 2007. Randomly amplifiied polymorphic DNA (RAPD) In Z. Liu, ed. Aquaculture Genome Technology. Blackwell Publishing, Auburn, p. 21-28.

Nakadate, M., Shikano, T., \& Taniguchi, N. 2003. Inbreeding depression and heterosis in various quantitative traits of the guppy, Poecilia reticulata. Aquaculture, 220: 219 226.

Pariset, L., Savarese, M.C., Cappuccio, I., \& Valentini, A. 2003. Use of microsatellites for genetic variation and inbreeding analysis in Sarda sheep flocks of central Italy. J. of Animal Breeding and Genetics, 120: 425432.

Romana-Eguia, M.R.R., Ikeda, M., Basiao, Z.U., \& Taniguchi, N. 2005. Genetic changes du- 
ring mass selection for growth in Nile tilapia, Oreochromis niloticus (L.), assessed by microsatellites. Aquaculture Research, 36: 69-78.

Sanchez, L., Bijma, P., \& Woolliams, J.A. 2003. Minimizing inbreeding by managing genetic contributions across generations. Genetics, 164: 1589-1595.

Shikano, T. \& Taniguchi, N. 2003. DNA markers for estimation of inbreeding depression and heterosis in the guppy, Poecilia reticulata. Aquaculture Research, 34: 905 911.

Tave, D. 1999. Inbreeding and broodstock management, Fisheries Technical Paper, FAO, Rome, 392: 122.
Williams, J.G.K., Kubelik, A.R., Livak, K.J., Rafalski, J.A., \& Tingey, S. 1990. DNA polymorphisms by arbitrary primers are useful as genetic markers. Nucleic Acids Res., 18: 65365351.

Wright, J.M. \& Bentzen, P. 1994. Microsatellites: genetic markers for the future. Reviews in Fish Biology and Fisheries, 4: 384-388.

Yoon, J.M. \& Kim, G.W. 2001. Randomly amplified polymorphic DNA-polymerase chain reaction analysis of two different populations of cultured Korean catfish Silurus asotus. J. of Biosciences, 26:641-647. 